\title{
KETOGENESIS IN RAT-LIVER MITOCHONDRIA: STIMULATION BY PALMITYL-COENZYME A
}

\author{
W.J. VAARTJES, M. LOPES-CARDOZO and S.G. VAN DEN BERGH* \\ Laboratory of Veterinary Biochemistry, State University of Utrecht, Biltstraat 172, Utrecht, The Netherlands
}

Received 10 July 1972

\section{Introduction}

It is well-known that the movement of adenine nucleotides (AdN) across the inner mitochondrial membrane is markedly decreased both by unsaturated [14] and by saturated [4-6] long-chain fatty acids. A similar effect is displayed by palmityl-CoA as demonstrated recently with isolated mitochondria of rat heart [7] and rat liver [5, 6, 8-10]. In fact, long chain acyl-CoA esters are much stronger inhibitors of mitochondrial AdN translocation than the corresponding free fatty acids and carnitine esters [6]. Therefore, long-chain acyl-CoA compounds such as palmityl$\mathrm{CoA}$ are the more likely candidates for the regulation of cell metabolism at the level of mitochondrial AdN transport.

For a better appreciation of the possible physiological role of this inhibitory effect of palmityl-CoA, some of its metabolic implications in isolated rat-liver mitochondria were studied. In the present report the influence of small amounts of extramitochondrial palmityl-CoA on palmitate oxidation and concomitant ketogenesis is shown. Our results clearly indicate that the inhibition by palmityl-CoA of ADP uptake in the mitochondria is reflected in increased 3-hydroxybutyrate/acetoacetate (HB/Acac) ratios and in preferential conversion of acetyl-CoA (AcCoA) into ketone bodies. In a following publication [11] the stimulation of pyruvate carboxylation by added palmityl-CoA will be discussed.

\footnotetext{
* To whom to address all correspondence.
}

\section{Methods and materials}

Rat-liver mitochondria were isolated according to Myers and Slater [12] and washed once more in order to remove all endogenous carnitine. Treatment of mitochondria with Nagarse was performed essentially as described by Pande and Blanchaer [13].

Total AcCoA generated during $\beta$-oxidation was calculated from the observed oxygen consumption and the accumulation of ketone bodies, acetylcarnitine and citrate. Full details of this calculation and its underlying assumptions are given elsewhere $[14,15]$. The acetyl-ratio is defined as that part of the total $\mathrm{AcCoA}$ that is converted into ketone bodies.

Oxygen uptake was measured at $25^{\circ}$ with a Gilson Respirometer. The standard reaction medium contained $50 \mathrm{mM}$ sucrose, $5 \mathrm{mM} \mathrm{MgCl}_{2}, 2 \mathrm{mM}$ EDTA,

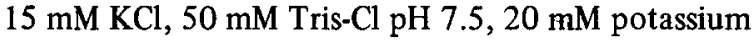
phosphate $\mathrm{pH} 7.5,20 \mathrm{mM}$ glucose, $2.6 \mathrm{U}$ of hexokinase, $0.5 \mathrm{mM}$ ADP and $0.5 \mathrm{mM}$ L-malate. Malate was included in order to lower the control values of the acetyl-ratio. Reactions were started by addition of mitochondria. Final volume, $2.0 \mathrm{ml}$. After $16 \mathrm{~min}$ $\mathrm{HClO}_{4}$ was added and metabolites were assayed spectrophotometrically in the deproteinized supernatants using standard enzymic me thods.

L-carnitine chloride was a generous gift of Otsuka Pharm. Fact. (Osaka). L-octanoylcarnitine and L-linoleylcarnitine were kindly donated by Dr. J. Bremer and Dr. B.O. Christophersen (Oslo). Nagarse (subtilopeptidase A) was obtained from Serva. Bovine serum albumin (BSA), fraction V, was defatted and dialyzed before use [16]. Hexokinase was also dialyzed and its activity (U) after dialysis was measured as glucose6-phosphate production ( $\mu \mathrm{moles} / \mathrm{min}$ ) at $25^{\circ}$ in the above-mentioned standard medium, ADP being re- 
Table 1

Influence of acyl-CoA esters on palmitate oxidation.

\begin{tabular}{lllll}
\hline Additions & $\begin{array}{l}\Delta 0 \\
(\mu \text { atoms })\end{array}$ & $\begin{array}{l}\Delta \text { AcCoA } \\
(\mu \text { moles })\end{array}$ & $\begin{array}{l}\text { Acetyl- } \\
\text { ratio }\end{array}$ & $\begin{array}{l}\text { HB/Acac } \\
\text { ratio }\end{array}$ \\
\hline None & 10.34 & 2.19 & 0.15 & 0.23 \\
Palmityl-CoA & 4.04 & 2.18 & 0.82 & 2.56 \\
Octanoyl-CoA & 10.01 & 2.16 & 0.17 & 0.20 \\
CoASH & 4.66 & 1.54 & 0.49 & 1.53 \\
Atractylate & 4.51 & 1.87 & 0.59 & 1.29 \\
Palmityl-CoA + BSA & 11.47 & 2.64 & 0.20 & 0.30 \\
\hline
\end{tabular}

The standard reaction medium (see Methods) was supplemented with $0.5 \mathrm{mM}$ palmitate. Further additions: palmityl-CoA (3.1 nmoles/mg protein), octanoyl-CoA (2.6 nmoles $/ \mathrm{mg}$ protein), $0.1 \mathrm{mM} \mathrm{CoASH,} 4.5 \mu \mathrm{g}$ atractylate, $15 \mathrm{mg}$ BSA. Mitochondrial protein, $10.2 \mathrm{mg}$.

placed by $5 \mathrm{mM}$ ATP. Other biochemicals and experimental details were as previously described [6].

\section{Results and discussion}

The presence of exogenous palmityl-CoA during palmitate oxidation increased the $\mathrm{HB} / \mathrm{Acac}$ ratio and acetyl-ratio far beyond their control values, as shown in table 1 (lines 1 and 2). A half-maximal stimulation of the acetyl-ratio was observed at a concentration of palmityl-CoA of about $5 \mathrm{nmoles} / \mathrm{mg}$ protein (table 2). In view of the inhibition of mitochondrial $A d N$ translocation by long-chain acyl-CoA esters [5-10] these observations can be explained as follows. Due to the interference of palmityl-CoA with ADP uptake, the intramitochondrial phosphate potential is in- creased. This in turn causes a higher reduction level of the mitochondrial nicotinamide nucleotides [17] which is reflected in the increased $\mathrm{HB} / \mathrm{Acac}$ ratio [18] At elevated $\mathrm{NADH} / \mathrm{NAD}^{+}$ratios, the intramitochondrial level of oxaloacetate is lowered. As a consequence $[14,15,19-21 ;$ cf. 22], citrate synthesis will decrease and AcCoA is preferentially diverted towards ketone body formation. Control experiments (not shown) confirmed that the palmityl-CoA effect was not due to an inhibition of hexokinase activity by palmityl-CoA.

Table 1 further shows: i) a negligible effect of octanoyl-CoA, in keeping with the observed lack of inhibition of ADP uptake by this compound [6]; ii) a suppression of the palmityl-CoA effect by excess BSA, and iii) pronounced effects of atractylate and $\mathrm{CoASH}$, similar to that of palmityl-CoA.

Table 2

Palmitate oxidation at various concentrations of added palmityl-CoA.

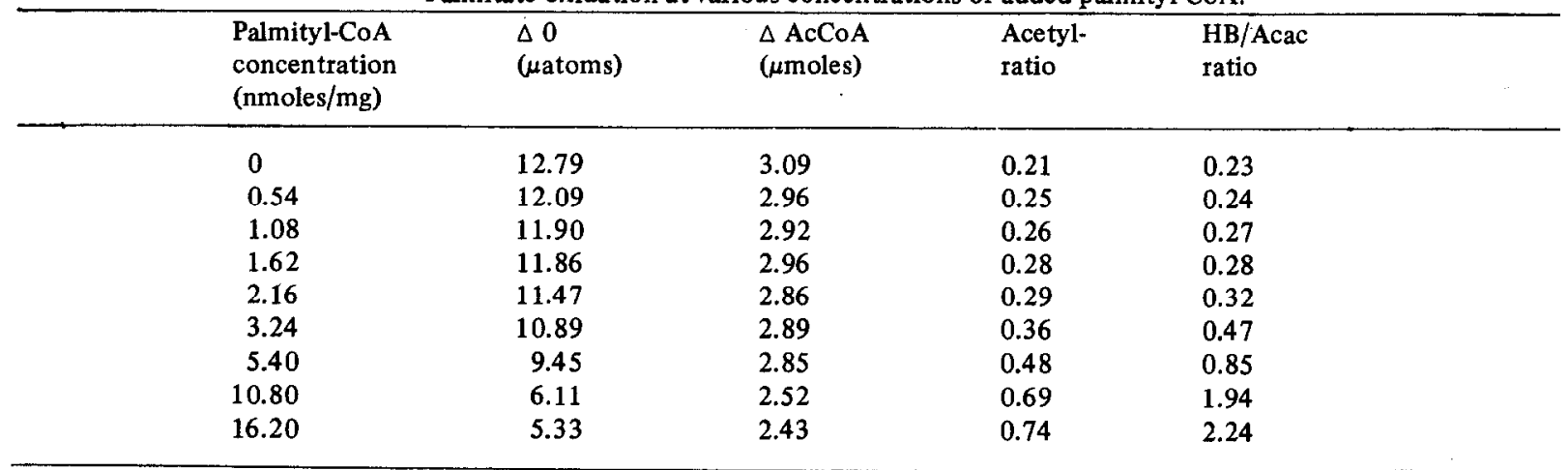

The standard reaction medium was supplemented with $0.5 \mathrm{mM}$ palmitate and various concentrations of palmityl-CoA. Mitochondrial protein, $9.2 \mathrm{mg}$. 


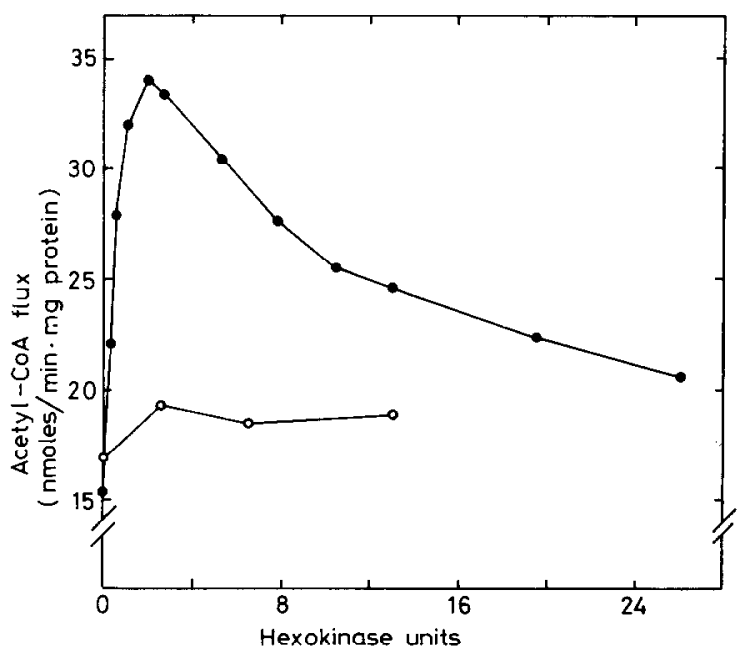

Fig. 1. Rate of palmitate oxidation as a function of hexokinase concentration. To the standard reaction medium $0.4 \mathrm{mM}$ palmitate (complexed with BSA in a molar ratio of 5:1) and varying amounts of hexokinase were added. Mitochondrial protein, $9.3 \mathrm{mg}$. No further additions; (o-o-o); with 25 $\mu \mathrm{M}$ CoASH, $0.25 \mathrm{mM}$ glutathione and $0.5 \mathrm{mM}$ L-carnitine:

$$
(\bullet) \text {. }
$$

The effect of added CoASH was already discussed earlier [6] : In ATPase experiments it was observed that in the presence of $\mathrm{Mg}^{2+}$, ATP, palmitate and CoASH the "external" palmityl-CoA synthetase [23] builds up inhibitory levels of extramitochondrial palmityl-CoA, provided carnitine is absent. Obviously, this external activation can proceed equally well in oxidation experiments in the presence of hexokinase [cf. 24]. The data shown in fig. 1 substantiate this conclusion. In the presence of carnitine and $\mathrm{CoASH}$, the oxidation of palmitate is mediated mainly by ex, ternal activation [23]. Fig. 1 shows that moderate concentrations of hexokinase enhance the AcCoA flux by release of respiratory control, whereas the AcCoA flux gradually slows down at higher hexokinase levels. For comparison, the oxidation of palmitate in a medium without added CoASH and carnitine permitting only intramitochondrial palmitate activation is also shown.

As the results of fig. 1 predict, the effects of added CoASH on palmitate oxidation are partially counteracted by an excessive amount of hexokinase (table 3 , exp. 1). L-carnitine, lowering the concentration of external palmityl-CoA by the formation of L-palmitylcarnitine, is more effective in reversing the effects of added CoASH: Virtually no effect of CoASH is observed (table 3, exp. 2) with mitochondria in which the palmityl-CoA synthetase localized in the outer mitochondrial membrane is destroyed by preincubation with Nagarse $[13,24,25]$. The effect of addition of $2:$ actylate shows that the inner membrane of the mitochondria is intact after Nagarse treatment.

In short, if rat-liver mitochondria are allowed to oxidize palmitate (mediated by internal activation) in the presence of $\mathrm{CoASH}$, a concomitant synthesis

Table 3

Effect of added CoASH on palmitate oxidation in normal and Nagarse-treated mitochondria.

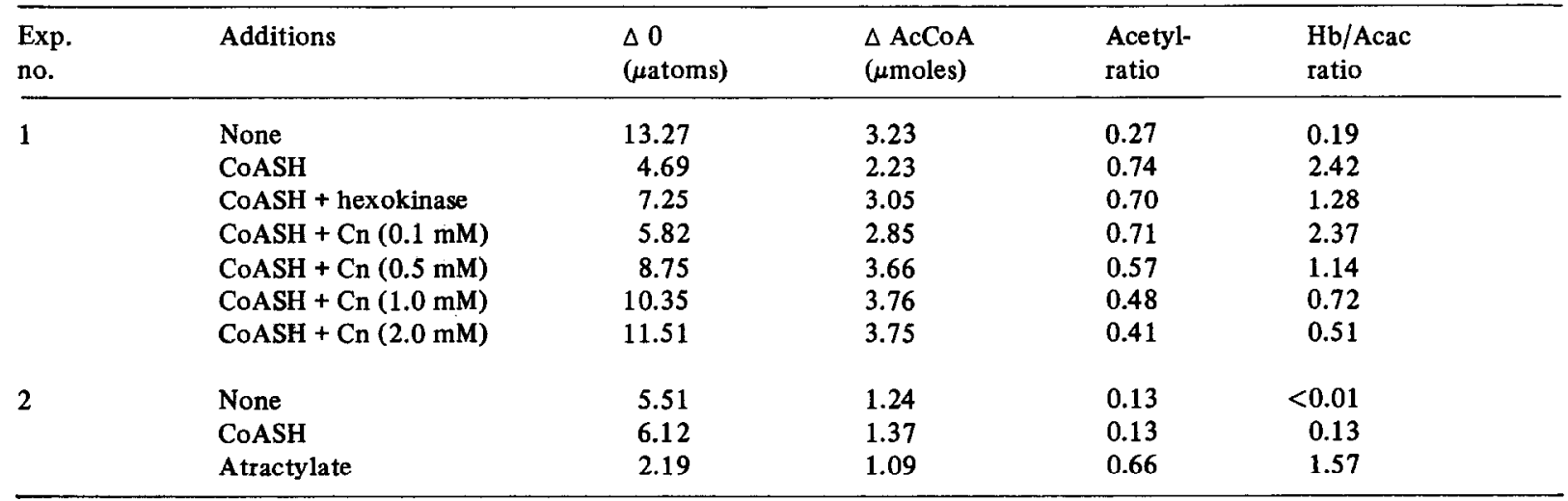

To the standard reaction medium $0.5 \mathrm{mM}$ palmitate was added. Further additions: $0.1 \mathrm{mM}$ CoASH, $13 \mathrm{U}$ of hexokinase, varying amounts of $\mathrm{L}$-carnitine $(\mathrm{Cn})$ and $4.5 \mu \mathrm{g}$ atractylate. Mitochondrial protcin, $8.4 \mathrm{mg}$ (exp. 1) and $9.7 \mathrm{mg}$ (exp. 2 ). In exp. $1 \mathrm{normal}$ mitochondria were used; in exp. 2 the mitochondria were pretreated with Nagarse $(9.1 \mu \mathrm{g} / \mathrm{mg}$ mitochondrial protein). 
Table 4

Palmitylcarnitine oxidation as affected by added $\mathrm{CoASH}$.

\begin{tabular}{|c|c|c|c|c|c|}
\hline $\begin{array}{l}\text { Exp. } \\
\text { no. }\end{array}$ & Additions & $\begin{array}{l}\triangle 0 \\
\text { ( } \mu \text { atoms) }\end{array}$ & 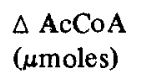 & $\begin{array}{l}\text { Acetyl- } \\
\text { ratio }\end{array}$ & $\begin{array}{l}\text { HB/Acac } \\
\text { ratio }\end{array}$ \\
\hline \multirow[t]{5}{*}{1} & None & $7.07(10.69)$ & $2.39(2.93)$ & $0.54(0.38)$ & $0.38(0.08)$ \\
\hline & CoASH $(2 \mu \mathrm{M})$ & $6.52(10.27)$ & $2.41(2.91)$ & $0.61(0.41)$ & $0.46(0.07)$ \\
\hline & CoASH $(5 \mu \mathrm{M})$ & $5.29(10.53)$ & $2.28(2.96)$ & $0.69(0.40)$ & $0.61(0.07)$ \\
\hline & CoASH $(10 \mu \mathrm{M})$ & $3.76(10.76)$ & $1.77(3.05)$ & $0.73(0.41)$ & $2.25(0.11)$ \\
\hline & CoASH $(80 \mu \mathrm{M})$ & $3.79(3.16)$ & $1.66(1.54)$ & $0.72(0.74)$ & $2.75(8.50)$ \\
\hline \multirow[t]{4}{*}{2} & None & 6.46 & 2.34 & 0.63 & 0.19 \\
\hline & CoASH & 3.31 & 1.73 & 0.86 & 1.24 \\
\hline & СCCP & 6.07 & 2.16 & 0.62 & 0.12 \\
\hline & $\mathrm{CoASH}+\mathrm{CCCP}$ & 5.23 & 1.96 & 0.66 & 0.12 \\
\hline
\end{tabular}

Exp. 1: The standard reaction medium was supplemented with $0.275 \mathrm{mM} \mathrm{L-palmitylcarnitinc} \mathrm{and} \mathrm{varying} \mathrm{concentrations} \mathrm{of}$ CoASH. Values in brackets represent incubations with $0.5 \mathrm{mM}$ L-carnitine. Mitochondrial protein, $6.9 \mathrm{mg}$. Exp. $2:$ To the standard reaction medium $0.18 \mathrm{mM}$ L-palmitylcarnitine was added. Further additions: $100 \mu \mathrm{M}$ CoASH, $0.9 \mu \mathrm{M}$ carbonylcyanide $m$-chlorophenylhydrazone $(\mathrm{CCCP})$ and $10 \mathrm{mg}$ BSA. Mitochondrial protein, $5.4 \mathrm{mg}$.

and accumulation of external palmityl-CoA occurs leading to marked increases in $\mathrm{HB} / \mathrm{Acac}$ ratios and acetyl-ratios.

Analogous conclusions may be drawn from the effect of CoASH on L-palmitylcarnitine oxidation (table 4, exp. 1). In this case palmityl-CoA synthesis is effected by the carnitine palmityltransferase reaction [26]. At low CoASH concentrations addition of $0.5 \mathrm{mM}$ L-carnitine can protect against the effect of CoASH. From the observation that the uncoupler CCCP abolishes the effect of added CoASH (table 4, exp. 2), it may be concluded that the shifts in $\mathrm{HB} / \mathrm{Acac}$ ratio and acetyl-ratio caused by the addition of CoASH are really due to the induced respiratory control.

The question whether or not inhibition of mitochondrial AdN transport by palmityl-CoA plays a role in vivo still remains open. An overwhelming number of enzymes have been reported to be inhibited by palmityl-CoA [e.g., 27-32]. The diversity of these enzymes and the almost complete irreversibility of the inhibition which is observed in many cases have aroused serious doubts as to the physiological significance of these inhibitory effects [3032]. On the other hand, the inhibition of $\operatorname{AdN}$ translocation by palmityl-CoA is competitive with respect to $A d N$; it is readily reversible with BSA and it is observed at relatively low non-detergent concentrations of palmityl-CoA $[6,7,9,10]$.

With some enzymes, the inhibition by palmityl$\mathrm{CoA}$ is reversed by palmitylcarnitine when both agents are present at comparable concentrations [28, 33]. However, the data reported in table 4 show that this is not the case with the $\Lambda \mathrm{dN}$ translocator. Moreover, in other experiments (not shown) the inhibition of the DNP-induced ATPase activity by a suboptimal amount of palmityl-CoA was enhanced by addition of palmitylcarnitine, linoleylcarnitine, palmitate or linoleate, whereas octanoylcarnitine had no effect [cf. 6].

The observation that BSA can reverse the inhibition by palmityl-CoA in vitro shows that the possible binding of palmityl-CoA to intracellular proteins could prevent palmityl-CoA effects in vivo. This possibility cannot be excluded completely at the moment. Hepatic levels of long-chain acyl-CoA are elevated to about $130 \mathrm{nmoles} / \mathrm{g}$ wet wt in starvation $[27,34]$. Assuming the protein content of rat liver to be $165 \mathrm{mg} / \mathrm{g}$ wet wt [cf. 35], and the intracellular distribution of long-chain acyl-CoA to be homogeneous, one arrives at a long-chain acyl-CoA concentration of 0.8 nmole per $\mathrm{mg}$ protein. This value exceeds 
the $K_{\mathrm{i}}$ of the AdN translocator for palmityl-CoA with respect to $\mathrm{ADP}(0.5 \mathrm{nmole} / \mathrm{mg}$ protein $)$ calculated for isolated mitochondria in our preceding paper [6]. It should be noted, however, that differences in the binding affinities of the various proteins, competition of fatty acids and fatty acyl-esters for the same binding sites as well as compartmentation may introduce errors in the above calculation. For instance, a relatively large part of the total long-chain acyl-CoA could well be present in the mitochondrial matrix since rat-liver contains $60 \mathrm{mg}$ mitochondrial protein $/ \mathrm{g}$ wet wt [36] and 2 nmoles intramitochondrial $\mathrm{CoASH} / \mathrm{mg}$ mitochondrial protein [37]. As yet it is not known whether intramitochondrial long-chain acyl-CoA contributes to the inhibition of AdN translocation.

The increased HB/Acac ratios and the enhanced ketogenesis, observed in our in vitro incubations upon addition of palmityl-CoA, are found in vivo in most metabolic states with a rapid rate of fatty-acid oxidation $[18,20,34]$. In this connection it is interesting to note that McLean et al. [34], comparing different metabolic states, concluded that only in the liver of the starved rat the mitochondrial phosphate potential is increased. On the other hand, the cy toplasmic phosphate potential is lowered in starvation [38]. It may well be that the phosphate potentials of mitochondria and cytoplasm are out of equilibrium as a consequence of the inhibition of the AdN translocator by long-chain acyl-CoA, since the level of the latter is known to be elevated in starvation $[27,34]$.

In conclusion, long-chain acyl-CoA compounds, modifying the rate of AdN transport across the mitochondrial inner membrane, may play a role in the regulation of ketogenesis in vivo, especially in starvation and in starvation followed by refeeding fat.

\section{Acknowlegements}

The skillful technical assistance of Miss W.J. Klazinga and Miss T.A. Wisserhof is gratefully acknowledged. This investigation was supported in part by the Netherlands Foundation for Chemical Research (S.O.N.) with financial aid from the Netherlands Organization for the Advancement of Pure Research (Z.W.O.).

\section{References}

[1] L. Wojtczak and H. Zaluska, Biochem Biophys. Res. Commun. 28 (1967) 76.

[2] L.Wojtczak, K. Bogucka, M.G. Sarzala and H. Zaluska, in: Mitochondria-Structure and Function, eds. L. Ernster and Z. Drahota (Academic Press, London and New York, 1969) p. 79.

[3] S.G. van den Bergh, C.P. Modder, J.H.M. Souverijn and H.C.J.M. Pierrot, in: Mitochondria-Structure and Function, eds. L. Ernster and Z. Drahota (Academic Press, London and New York, 1969) p. 137.

[4] W.J. Vaartjes and S.G. van den Bergh, in: Energy Transduction in Respiration and Photosynthesis, eds. E. Quagliariello, S. Papa and C.S. Rossi (Adriatica Editrice, Bari, 1971) p. 413.

[5] W.J. Vaartjes and S.G. van den Bergh, Abstr. Commun. Meet. Fed. Eur. Biochem. Soc. 7 (1971) 227.

[6] W.J. Vaartjes, A. Kemp Jr, J.II.M. Souverijn and S.G. van den Bergh, FEBS letters 23 (1972) 303.

[7] S.V. Pande and M.C. Blanchaer, J. Biol. Chem. 246 (1971) 402 .

[8] A.L. Shug, E. Lerner, C. Elson and E. Shrago, Biochem. Biophys. Res. Commun. 43 (1971) 557.

[9] E. Lerner, A.L. Shug, C. Elson and E. Shrago, J. Biol. Chem. 247 (1972) 1513.

[10] R.A. Harris, B. Farmer and T. Ozawa, Arch. Biochem. Biophys. 150 (1972) 199.

[11] M. Lopes-Cardozo, W.J. Vaartjes and S.G. van den Bergh, in preparation.

[12] D.K. Myers and E.C. Slater, Biochem.J. 67 (1957) 558.

[13] S.V. Pande and M.C. Blanchaer, Biochim. Biophys. Acta 202 (1970) 43.

[14] S.G. van den Bergh and M. Lopes-Cardozo, in: Energy Transduction in Respiration and Photosynthesis, eds. E. Quagliariello, S. Papa and C.S. Rossi (Adriatica Editrice, Bari, 1971) p. 421.

[15] M. Lopes-Cardozo and S.G. van den Bergh, submitted for publication.

[16] R.F. Chen, J. Biol. Chem. 242 (1967) 173.

[17] B. Chance and G.R. Williams, Advan. in Enzymol. 17 (1956) 65.

[18] D.H. Williamson, P. Lund and H.A. Krebs, Biochem. J. 103 (1967) 514.

[19] A.L. Lehninger, J. Biol. Chem. 164 (1946) 291.

[20] O. Wieland and G. Löffler, Biochem. Z. 339 (1963) 204.

[21] M.S. Olson and J.R. Williamson, J. Biol. Chem. 246 (1971) 7794.

[22] P.B. Garland, D. Shepherd, D. G. Nicholls, D.W. Yates and P.A. Light, in: The Citric Acid Cycle, ed. J.M. Lowenstein (Dekker, New York, 1969) p. 163.

[23] A. van Tol and W.C. Hülsmann. Biochim. Biophys. Acta 223 (1970) 416.

[24] J.W. de Jong and W.C. Hülsmann, Biochim. Biophys. Acta 210 (1970) 499.

[25] J.W. de Jong and W.C. Hülsmann, Biochim. Biophys. Acta 197 (1970) 127. 
[26] K.R. Norum, Biochim. Biophys. Acta 89 (1964) 95.

[27] P.K. Tubbs and P.B. Garland, Biochem. J. 93 (1964) 550.

[28] N.R. Marquis, R.P. Francesconi and C.A. Villee, Advan. Enzyme Regul. 6 (1968) 31.

[29] S.V. Pande and J.F. Mead, J. Biol. Chem. 243 (1968) 6180.

[30] P.A. Srere, Biochim. Biophys. Acta 106 (1965) 445.

[31] K. Taketa and B.M. Pogell, J. Biol. Chem. 241 (1966) 720.

[32] W.L. Zahler and W.W. Clelands, Biochim. Biophys. Acta 176 (1969) 699.

[33] I.B. Fritz, Biochem. Biophys. Res. Commun. 22 (1966) 744.
[34] P. McLean, K.A. Gumaa and A.L. Greenbaum, FEBS Letters 17 (1971) 345 .

[35] A. Spencer, L. Corman and J.M. Lowenstein, Biochem. J. 93 (1964) 378.

[36] R. Scholz and Th. Bücher, in: Control of Energy Metabolism, eds. B. Chance, R.W. Estabrook and J.R. Williamson (Academic Press, New York and London, 1965) p. 393

[37] P.B. Garland, D. Shepherd and D.W. Yates, Biochem. J. 97 (1965) 587.

[38] R.L. Veech, L. Raijman and H.A. Krebs, Biochem. J. 117 (1970) 499. 